\title{
Variabilidade espacial e temporal da precipitação no Estado do Tocantins, Brasil
}

\author{
Spatial and temporal variability of precipitation in Tocantins State, Brazil \\ Variabilidad espacial y temporal de la precipitación en el Estado de Tocantins, Brasil
}

Recebido: 04/03/2021 | Revisado: 11/03/2021 | Aceito: 15/03/2021 | Publicado: 21/03/2021

\author{
Virgílio Lourenço Silva Neto \\ ORCID: https://orcid.org/0000-0002-1004-0191 \\ Universidade Federal do Tocantins, Brasil \\ Instituto Federal de Educação, Ciência e Tecnologia do Tocantins, Brasil \\ E-mail: virgilio.neto@ifto.edu.br \\ Lucas Barbosa e Souza \\ ORCID: https://orcid.org/0000-0001-7957-088X \\ Universidade Federal do Tocantins, Brasil \\ E-mail: lbsgeo@uft.edu.br \\ Marcelo Ribeiro Viola \\ ORCID: https://orcid.org/0000-0002-3910-0987 \\ Universidade Federal de Lavras, Brasil \\ E-mail: marcelo.viola@ufla.br \\ Marco Antonio Vieira Morais \\ ORCID: https://orcid.org/0000-0002-6699-5990 \\ Instituto Federal de Educação, Ciência e Tecnologia do Mato Grosso, Brasil \\ E-mail: marco.morais@bag.ifmt.edu.br
}

\begin{abstract}
Resumo
O objetivo deste estudo é realizar o mapeamento da precipitação pluvial mensal e anual com base em procedimentos da geoestatística e analisar as tendências espaciais e temporais das chuvas para o estado do Tocantins. Foram constituídas séries históricas de precipitação mensal e anual em um período padronizado entre 1988 e 2019, gerando-se valores médios para proceder com a espacialização e interpolação dos dados. A análise exploratória dos dados foi realizada a partir de gráficos de tendência para a precipitação anual, que demonstram o comportamento geral apresentado nesta análise entre os diferentes eventos em estudo, submetendo os dados ao teste de tendências de Mann-Kendall. Procedeuse com o ajuste do modelo de semivariograma teórico, a partir da obtenção dos valores para os parâmetros estruturais como o efeito pepita, a contribuição e o alcance. Para a precipitação mensal, o grau de dependência espacial para os modelos com melhor desempenho variou entre $72,4 \%$ e $100 \%$. Sob o ponto de vista espacial, o sudeste do Tocantins apresentou os menores valores de precipitação e o mês de dezembro os maiores. Já pelo viés temporal, durante o mês de julho, a porção centro-sul tocantinense apresentou índices muito reduzidos, entre 0 e $2 \mathrm{~mm}$, enquanto nos meses mais chuvosos, de dezembro a março, a precipitação mensal variou entre $382 \mathrm{~mm}$ (janeiro) e $262 \mathrm{~mm}$ (fevereiro). Os meses entre julho e setembro são o período crítico de estiagem no Tocantins, quando a precipitação no período apresentou variação de 0 a $25 \mathrm{~mm}$.
\end{abstract}

Palavras-chave: Geoestatística; Pluviosidade; Mann-Kendall.

\begin{abstract}
This study aimed to map monthly and annual rainfall based on geostatistical procedures and to analyze spatial and temporal rainfall trends for the state of Tocantins. Historical series of monthly and annual precipitation were constituted in a standardized period between 1988 and 2019, generating average values to proceed with the spatialization and interpolation of the data. The exploratory analysis of the data was performed based on trend graphs for annual precipitation, which demonstrate the general behavior presented in this analysis between the different events under study, submitting the data to the Mann-Kendall trend test. We proceeded with the adjustment of the theoretical semivariogram model, from obtaining the values for the structural parameters such as the nugget effect, the contribution and the reach. For monthly rainfall, the degree of spatial dependence for the models with the best performance varied between $72.4 \%$ and $100 \%$. From the spatial point of view, the southeast of Tocantins presented the lowest precipitation values and the month of December the highest. As for the temporal bias, during the month of July, the center-south portion of Tocantins presented very low rates, between 0 and $2 \mathrm{~mm}$, while in the rainiest months, from December to March, the monthly precipitation varied between $382 \mathrm{~mm}$ (January) and $262 \mathrm{~mm}$ (February). The months between July and September are the critical drought period in Tocantins, when the rainfall in the period varied from 0 to $25 \mathrm{~mm}$.
\end{abstract}

Keywords: Geostatistics; Rainfall; Mann-Kendall. 


\begin{abstract}
Resumen
El objetivo de este estudio es mapear las precipitaciones mensuales y anuales con base en procedimientos geoestadísticos y analizar las tendencias espaciales y temporales de las precipitaciones para el estado de Tocantins. Se constituyeron series históricas de precipitación mensual y anual en un período estandarizado entre 1988 y 2019 , generando valores promedio para proceder con la espacialización e interpolación de los datos. El análisis exploratorio de los datos se realizó con base en gráficas de tendencia de precipitación anual, las cuales demuestran el comportamiento general presentado en este análisis entre los diferentes eventos en estudio, sometiendo los datos a la prueba de tendencia de Mann-Kendall. Se procedió al ajuste del modelo de semivariograma teórico, a partir de la obtención de los valores de los parámetros estructurales como el efecto pepita, el aporte y el alcance. Para la precipitación mensual, el grado de dependencia espacial para los modelos con mejor desempeño varió entre $72,4 \%$ y $100 \%$. Desde el punto de vista espacial, el sureste de Tocantins presentó los valores de precipitación más bajos y el mes de diciembre los más altos. En cuanto al sesgo temporal, durante el mes de julio, la porción centro-sur de Tocantins presentó tasas muy bajas, entre 0 y $2 \mathrm{~mm}$, mientras que en los meses más lluviosos, de diciembre a marzo, la precipitación mensual varió entre $382 \mathrm{~mm}$ (enero ) y $262 \mathrm{~mm}$ (febrero). Los meses entre julio y septiembre son el período crítico de sequía en Tocantins, cuando la precipitación en el período varió de 0 a $25 \mathrm{~mm}$.
\end{abstract}

Palabras clave: Geoestadística; Lluvia; Mann-Kendall.

\title{
1. Introdução
}

A compreensão das características espaciais e temporais da precipitação pluvial de uma localidade é fundamental para a eficácia da gestão dos recursos hídricos de forma sustentável, ou seja, é preciso conhecer o comportamento pluvial para utilização da água no intuito de solucionar problemas existentes onde este recurso é escasso e prevenir problemas futuros como como conflitos pelo uso da água, inundações urbanas e falta de água para abastecimento público, já que a precipitação pluvial é o principal componente do ciclo hidrológico, diretamente responsável pela entrada da água numa bacia hidrográfica (Prólo et al., 2021). Tanto no âmbito das demandas para o consumo humano quanto para as atividades agrícolas, há a possibilidade de a precipitação ocasionar prejuízos em situações de excesso ou escassez, pois afeta diretamente o consumo doméstico, a irrigação, a qualidade e a disponibilidade hídrica de um modo geral (Oliveira et al., 2017).

Neste sentido, a "variabilidade climática e o aumento dos eventos meteorológicos [excepcionais], especialmente quanto à precipitação pluviométrica e à temperatura do ar, tem preocupado, tanto as autoridades governamentais, quanto os tomadores de decisão, em todos os segmentos da sociedade" (Andrade et al., 2018, p. 127). Diversas atividades antrópicas sofrem influência direta do clima em diferentes graus, sobretudo a agricultura, em que o clima é um fator condicionante para as diferentes culturas, que devem ser compatíveis com a oferta climática variável no tempo e no espaço, o que justifica o estudo da precipitação pela Climatologia e Agrometeorologia, assim como as tendências climáticas (Ely \& Dubreuil, 2017).

No que se refere aos dados de precipitação, Baptista e Severo (2018) afirmam que são consequência das características do clima de uma determinada região e que as séries históricas apresentam componentes como variabilidade, tendências, aleatoriedade e sazonalidade, que podem ser analisadas por meio de testes não paramétricos como o de Mann-Kendall, recomendado para a verificação de tendências em séries temporais de elementos climáticos.

Penereiro et al. (2016) afirmam que a análise da precipitação pluvial tem recebido atenção especial por parte da comunidade científica em função de sua influência nas condições da qualidade de vida das pessoas, produção energética, gestão da água e diversas outras atividades, como industriais e turísticas.

No mapeamento da precipitação pluvial, são empregados métodos de interpolação espacial, em que se destacam as técnicas geoestatísticas. Nelas, o "semivariograma é uma das ferramentas mais importantes dessa metodologia, pois permite determinar a amplitude da dependência espacial e descreve o comportamento da variável” (Gomes, 2011, p. 693). Já a estatística clássica considera que as realizações das variáveis aleatórias são independentes entre si, desconsiderando assim a influência entre observações vizinhas (Santos et al., 2011).

Diversos estudos sobre a precipitação foram realizados nos últimos anos, em diferentes abordagens, com foco na relação intensidade-duração-frequência, desagregação de chuvas diárias, precipitação máxima ou mínima provável, bem como a 
variabilidade espacial e temporal da precipitação pluvial. Dentre estes, podem ser mencionados os trabalhos de Viola et al. (2010), que avaliaram o desempenho de diferentes métodos de interpolação espacial para o mapeamento da precipitação pluvial; Gomes (2011), que realizou a análise geoestatística da precipitação pluvial do estado da Paraíba; Mello et al. (2012) estudaram a continuidade espacial das grandezas precipitação pluviométrica e erosividade da chuva em escala de tempo mensal e anual, aplicando procedimentos de geoestatísticas; Marcuzzo e Goularte (2013) caracterizaram o ano hidrológico, mapeando as chuvas nos períodos úmido e seco do estado do Tocantins; Santos et al. (2014), que abordaram a variabilidade da precipitação no estado do Pará; Penereiro et al. (2015), que apresentaram um diagnóstico sazonal sobre os comportamentos climáticos e hidrológicos na região da bacia hidrográfica do Tocantins-Araguaia; e Barros et al. (2020) que utilizaram a geoestatística como ferramenta para estudos da variabilidade da precipitação pluviométrica no estado de Pernambuco.

Diante do exposto, a questão norteadora é como a precipitação pluviométrica varia temporal e espacialmente no território tocantinense? Assim, o objetivo deste estudo é realizar o mapeamento da precipitação pluvial mensal e anual com base em procedimentos da geoestatística e analisar as tendências espaciais e temporais das chuvas para o estado do Tocantins, considerando o período entre 1989 e 2019.

\section{Metodologia}

A Unidade Federativa do Tocantins está localizada na Região Norte do Brasil, entre os paralelos 5'10'06" e 1327'59" de latitude sul e os meridianos $45^{\circ} 44^{\prime} 46^{\prime \prime}$ e $50^{\circ} 44^{\prime} 33^{\prime \prime}$ de longitude oeste, com área de $277.620,9 \mathrm{~km}^{2}$. Isto equivale a 3,26\% território brasileiro e a 7,2\% da região Norte do Brasil (Silva Neto et al., 2020a). Os biomas presentes no Estado são Amazônia (9\% do território do Tocantins) e o Cerrado em 91\% do território (IBGE, 2004).

Quanto à caracterização climática do estado, Souza et al. (2019) elaboraram uma proposta de classificação com base nos estudos de Thornthwaite e Matter para o Tocantins, em que foram destacadas três regiões climáticas homogêneas: I - região climática C1s2A'a': Clima subúmido seco, ao leste do Bico do Papagaio e extremo leste do estado; II - região climática C2wA'a': clima subúmido, predominante na maior parte do Tocantins, no sentido norte a sul, e III - região climática B1wA'a': clima úmido, predominante na porção sudoeste do Tocantins e uma pequena parte ao sudeste do estado.

Em uma etapa preliminar, foram utilizados dados de 93 estações pluviométricas, obtidos por meio do site Hidroweb, pertencentes à rede hidrometeorológica da Agência Nacional das Águas, conforme a Figura 1. Inicialmente, foram constituídas séries históricas de precipitação mensal e anual em um período padronizado entre 1988 e 2019 para cada estação, gerando-se valores médios para proceder com a espacialização e interpolação dos dados. É importante destacar que foram descartados os anos que continham falhas em suas séries históricas, sobretudo durante o período chuvoso, o que determinou um período médio padronizado de aproximadamente 30 anos.

A análise exploratória dos dados foi realizada a partir de gráficos de tendência para a precipitação anual, que demonstram o comportamento geral apresentado nesta análise entre as diferentes situações analisadas. O resultado desta etapa foi essencial para se avaliar a aplicação das técnicas geoestatísticas (Alves et al., 2016), os dados foram submetidos ao teste de tendências de Mann-Kendall ( $\alpha=0.05$ ). Para o mapeamento da precipitação média mensal e anual no Tocantins, as estações que apresentaram resultados menores que 0,05 no teste de tendência, foram descartadas antes da análise geoestatística e, consequentemente, da espacialização dos dados. Foi utilizado o software ArcGIS9.2® (ESRI, 2004). Foram adotadas a Projeção Cônica de Albers e o Datum SIRGAS 2000 para a produção dos mapas, conforme descrito por Silva Neto et al. (2020b). 
Figura 1 - Localização das estações pluviométricas utilizadas no mapeamento da precipitação pluvial e Modelo Digital de Elevação para o estado do Tocantins.

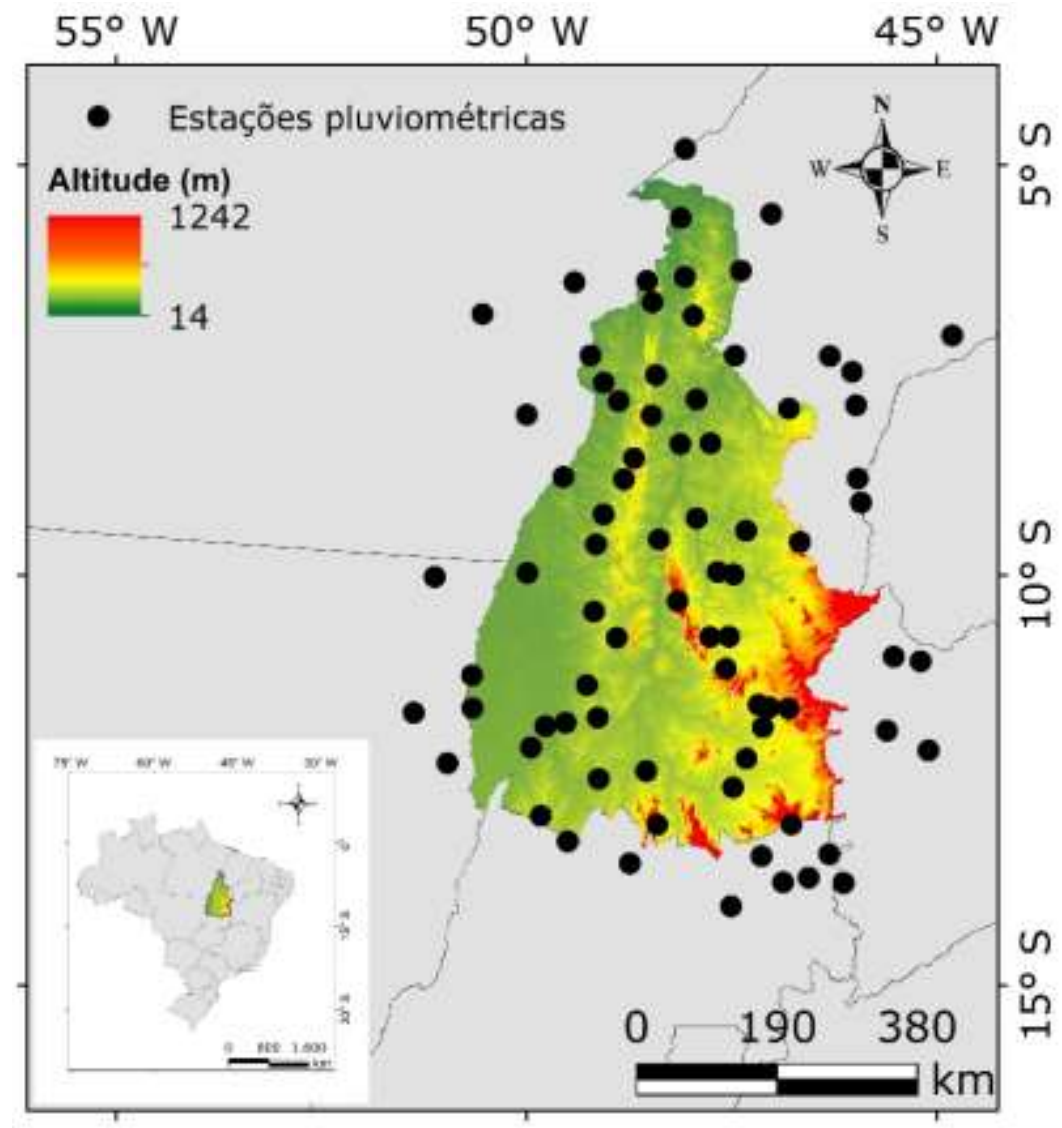

Fonte: ANA (2019); ASF DAAC (2021). Org. autores (2021)

É importante destacar que do total de 93 estações pluviométricas representadas pela Figura 1,34 estações estão fora do território tocantinense, porém, com relevância para o processo de interpolação na região de contorno. O Modelo Digital de Elevação (MDE) foi obtido através de ASF DAAC (2021) e utilizado para obtenção dos valores de altitude das estações pluviométricas, conforme Tabela 1.

Tabela 1 - Relação das estações pluviométricas utilizadas no presente estudo.

\begin{tabular}{rcccc}
\hline Código da Estação & Município-UF & Latitude & Longitude & Altitude (m) \\
\hline 949000 & Abreulândia-TO & $-9,624$ & $-49,155$ & 237 \\
1147000 & Almas-TO & $-11,579$ & $-47,174$ & 419 \\
1447000 & Alto Paraíso-GO & $-14,035$ & $-47,512$ & 1552 \\
945011 & Alto Parnaíba-MA & $-9,113$ & $-45,926$ & 286 \\
1249000 & Alvorada-TO & $-12,484$ & $-49,124$ & 315 \\
648001 & Ananás-TO & $-6,364$ & $-48,073$ & 195 \\
849002 & Araguacema-TO & $-8,802$ & $-49,556$ & 155 \\
1249001 & Araguaçu-TO & $-12,931$ & $-49,829$ & 293 \\
548000 & Araguatins-TO & $-5,648$ & $-48,125$ & 117 \\
749000 & Arapoema-TO & $-7,655$ & $-49,065$ & 221 \\
1246001 & Aurora do Tocantins-TO & $-12,714$ & $-46,409$ & 467 \\
746006 & Balsas-MA & $-7,523$ & $-46,034$ & 259 \\
950001 & Santana do Araguaia-PA & $-9,228$ & $-50,211$ & 214 \\
1249003 & Sandolândia-TO & $-12,099$ & $-49,948$ & 206 \\
1151000 & Alto Boa Vista-MT & $-11,675$ & $-51,376$ & -249 \\
846005 & Alto Parnaíba-MA & $-8,813$ & $-46,078$ & 295 \\
\hline
\end{tabular}




\begin{tabular}{|c|c|c|c|c|}
\hline 749001 & Araguaína-TO & $-7,323$ & $-49,224$ & 127 \\
\hline 746007 & Balsas-MA & $-7,929$ & $-45,989$ & 332 \\
\hline 547005 & Buritirana-MA & $-5,594$ & $-47,019$ & 231 \\
\hline 1346004 & Campos Belos-GO & $-13,037$ & $-46,777$ & 637 \\
\hline 847002 & Campos Lindos-TO & $-7,971$ & $-46,806$ & 291 \\
\hline 950002 & Pium-TO & $-9,970$ & $-49,994$ & 177 \\
\hline 747000 & Carolina-MA & $-7,323$ & $-47,464$ & 172 \\
\hline 848000 & Colinas-TO & $-8,053$ & $-48,482$ & 232 \\
\hline 1248001 & Peixe-TO & $-12,388$ & $-48,544$ & 319 \\
\hline 748001 & Bernardo Sayão-TO & $-7,878$ & $-48,879$ & 160 \\
\hline 1247000 & Conceição do Tocantins-TO & $-12,233$ & $-47,324$ & 413 \\
\hline 1146000 & Dianópolis-TO & $-11,625$ & $-46,811$ & 687 \\
\hline 949001 & Dois Irmãos do Tocantins-TO & $-9,257$ & $-49,064$ & 267 \\
\hline 1149000 & Dueré-TO & $-11,339$ & $-49,265$ & 231 \\
\hline 1349003 & Porangatu-GO & $-13,103$ & $-49,201$ & 352 \\
\hline 1048000 & Fátima-TO & $-10,764$ & $-48,902$ & 358 \\
\hline 1145004 & Formosa do Rio Preto-BA & $-10,993$ & $-45,527$ & 508 \\
\hline 650001 & Marabá-PA & $-6,815$ & $-50,539$ & 296 \\
\hline 1346002 & São Domingos-GO & $-13,686$ & $-46,566$ & 532 \\
\hline 1245014 & Barreiras-BA & $-12,126$ & $-45,644$ & 712 \\
\hline 1148000 & S. Valério da Natividade & $-11,531$ & $-48,295$ & 252 \\
\hline 1346006 & Correntina-BA & $-13,752$ & $-46,140$ & 959 \\
\hline 748002 & Nova Olinda-TO & $-7,561$ & $-48,423$ & 266 \\
\hline 1245004 & Barreiras-BA & $-12,135$ & $-45,104$ & 484 \\
\hline 649001 & Sapucaia-PA & $-6,795$ & $-49,549$ & 186 \\
\hline 1247005 & Fátima-TO & $-12,585$ & $-47,487$ & 341 \\
\hline 649000 & Marabá-PA & $-6,428$ & $-49,420$ & 134 \\
\hline 1145001 & Formosa do Rio Preto-BA & $-11,048$ & $-45,202$ & 486 \\
\hline 1149001 & Formoso do Araguaia-TO & $-11,797$ & $-49,525$ & 260 \\
\hline 747001 & Goiatins-TO & $-7,715$ & $-47,315$ & 191 \\
\hline 848001 & Guaraí-TO & $-8,832$ & $-48,817$ & 241 \\
\hline 1149002 & Gurupi-TO & $-11,737$ & $-49,136$ & 346 \\
\hline 845005 & Alto Parnaíba-MA & $-8,821$ & $-45,968$ & 310 \\
\hline 847001 & Itacajá-TO & $-8,392$ & $-47,763$ & 184 \\
\hline 848002 & Itaporã do Tocantins -TO & $-8,574$ & $-48,690$ & 341 \\
\hline 1047001 & Novo Acordo-TO & $-9,991$ & $-47,479$ & 221 \\
\hline 946003 & Lizarda-TO & $-9,597$ & $-46,673$ & 420 \\
\hline 1050000 & Luciara-MT & $-11,219$ & $-50,669$ & 191 \\
\hline 947001 & Rio Sono-TO & $-9,458$ & $-47,327$ & 331 \\
\hline 948000 & Miracema do Tocantins -TO & $-9,564$ & $-48,388$ & 199 \\
\hline 746008 & Riachão-MA & $-7,158$ & $-46,554$ & 486 \\
\hline 748003 & Muricilândia-TO & $-7,154$ & $-48,603$ & 197 \\
\hline 1147001 & Natividade-TO & $-11,697$ & $-47,728$ & 311 \\
\hline 1346001 & Nova Roma-GO & $-13,743$ & $-46,878$ & 626 \\
\hline 1145014 & Barreiras-BA & $-11,853$ & $-47,122$ & 370 \\
\hline 1047000 & Novo Acordo-TO & $-9,961$ & $-47,675$ & 211 \\
\hline 1349001 & Novo Planalto-GO & $-13,245$ & $-49,502$ & 291 \\
\hline 747009 & Palmeirante-TO & $-7,859$ & $-47,929$ & 168 \\
\hline 1248003 & Palmeirópolis-TO & $-13,042$ & $-48,407$ & 445 \\
\hline 1048001 & Paraíso do Tocantins-TO & $-10,165$ & $-48,399$ & 209 \\
\hline 1147002 & Pindorama do Tocantins-TO & $-11,140$ & $-47,577$ & 427 \\
\hline 648002 & Araguanã-TO & $-6,672$ & $-48,470$ & 157 \\
\hline 1049001 & Pium-TO & $-10,441$ & $-49,179$ & 286 \\
\hline 1047004 & Ponte Alta do Tocantins-TO & $-10,751$ & $-47,536$ & 329 \\
\hline 1347001 & Teresina de Goiás-GO & $-13,425$ & $-47,139$ & 365 \\
\hline 1145013 & Barreiras-BA & $-11,896$ & $-45,612$ & 730 \\
\hline 1147003 & Porto Alegre do Tocantins-TO & $-11,610$ & $-47,045$ & 379 \\
\hline 1047002 & Monte Carmo-TO & $-10,755$ & $-47,765$ & 294 \\
\hline 948001 & Pedro Afonso-TO & $-9,307$ & $-47,929$ & 199 \\
\hline 1249002 & Formoso do Araguaia-TO & $-11,839$ & $-49,772$ & 203 \\
\hline 746009 & Balsas-MA & $-7,331$ & $-46,308$ & 305 \\
\hline
\end{tabular}


Research, Society and Development, v. 10, n. 3, e44310313545, 2021

(CC BY 4.0) | ISSN 2525-3409 | DOI: http://dx.doi.org/10.33448/rsd-v10i3.13545

\begin{tabular}{rcccc}
\hline \multicolumn{5}{c}{} \\
\hline 850000 & Redenção-PA & $-8,044$ & $-50,001$ & 208 \\
1247002 & Conceição do Tocantins-TO & $-12,416$ & $-47,200$ & 341 \\
1245015 & São Desidério-BA & $-12,765$ & $-45,944$ & 827 \\
448000 & São Domingos do Capim-PA & $-4,804$ & $-48,069$ & 200 \\
1250001 & Novo Santo Antônio-MT & $-12,290$ & $-50,966$ & 214 \\
1346000 & São Domingos-GO & $-13,398$ & $-46,316$ & 657 \\
744000 & São Félix de Balsas-MA & $-7,081$ & $-44,813$ & 175 \\
1150001 & S. Félix do Araguaia-TO & $-11,620$ & $-50,663$ & 178 \\
548001 & São Sebastião do Tocantins-TO & $-5,260$ & $-48,207$ & 127 \\
1048005 & Palmas-TO & $-10,313$ & $-48,163$ & 410 \\
647000 & Tocantinópolis-TO & $-6,289$ & $-47,392$ & 142 \\
1348003 & Trombas-GO & $-13,513$ & $-48,745$ & 393 \\
848003 & Tupiratins-TO & $-8,399$ & $-48,130$ & 193 \\
951000 & Vila Rica-MT & $-10,019$ & $-51,123$ & 260 \\
647001 & Wanderlândia-TO & $-6,839$ & $-47,971$ & 246 \\
648000 & Xambioá-TO & $-6,413$ & $-48,533$ & 139 \\
\hline
\end{tabular}

Fonte: ANA (2019).

A Tabela 1 contém informações importantes sobre as estações pluviométricas utilizadas no presente estudo, como a localização e altitude. Das 93 estações pluviométricas, 59 estão localizadas no estado do Tocantins, cuja baixa altimetria é um fator que apresenta influência menor que outros fenômenos atmosféricos. A média da altimetria onde as estações estão localizadas é de 329 m, sendo a estação de Alto Paraíso, na região nordeste do estado de Goiás, a estação com altitude mais elevada (1552 m) e a estação de Araguatins, ao norte do Tocantins, a estação com menor altimetria (117 m).

Outra etapa com fundamental importância na análise geoestatística está no ajuste do modelo de semivariograma teórico, a partir da obtenção dos valores para os parâmetros estruturais de tais modelos, como o efeito pepita, a contribuição e o alcance. No presente estudo, foram testados os modelos esférico, exponencial e gaussiano, aplicando-se o método de ajuste dos Mínimos Quadrados Ponderados (MQP). Os modelos esférico, exponencial e gaussiano estão descritos nas Equações 1, 2 e 3, respectivamente.

$$
\begin{aligned}
& \gamma(h)=C_{0}+C_{1} \cdot\left[\frac{3}{2} \cdot\left(\frac{h}{a}\right)-\frac{1}{2} \cdot\left(\frac{h}{a}\right)^{3}\right], \text { se } 0<h<a ; \gamma(h)=C 0+C 1 ; h \geq a \\
& \gamma(h)=C_{0}+C_{1} \cdot\left[1-\exp \left(\frac{-3 \cdot h}{a}\right)\right], \text { se } 0<h<a ; \gamma(h)=C 0+C 1 ; h>a \\
& \gamma(h)=C_{0}+C_{1} \cdot\left\{1-\exp \left[-3 \cdot\left(\frac{h}{a}\right)^{2}\right]\right\}, \text { se } 0<h<a ; \gamma(h)=C 0+C 1 ; h>a
\end{aligned}
$$

Em que,

$\gamma(h)=$ semivariância,

$\mathrm{C}_{1}=$ contribuição do semivariograma (patamar menos o efeito pepita),

$a=$ alcance,

$\mathrm{C}_{0}=$ efeito pepita, $\mathrm{e}$

$h=$ distância entre os pares de pontos.

A dependência espacial dos modelos ajustados de semivariograma foi analisada com base no cálculo do grau de dependência espacial (GDE), obtido de acordo com o descrito por Cambardella et al. (1994):

$$
G D E=\left(\frac{C_{1}}{C_{0}+C_{1}}\right) \cdot 100
$$

Considerando o GDE, pode-se adotar a seguinte classificação: GDE < 25\% (fraco), entre 25 e $75 \%$ (moderado) e > $75 \%$ (forte) (Cambardella et al., 1994). 
Para avaliar qual modelo de semivariograma obteve o melhor desempenho, procedeu-se com a validação cruzada. Foi determinado o erro médio percentual absoluto (EMPA), identificando o modelo que apresentou o menor erro de estimativa, e que será considerado para o mapeamento da precipitação em cada uma das situações analisadas. Mesmo procedimento foi adotado em outros estudos, como os de Silva Neto et al. (2020b) e Prólo et al. (2021). Já o Bias (viés estatístico) foi determinado pelas médias da diferença entre as estimativas e as observações, apontando o erro sistemático do interpolador (subestimativa ou superestimativa). O valor do Bias equivale ao percentual de viés da variável estimada com relação à variável observada.

O EMPA e o Bias foram obtidos em \%, conforme Cambardella (1994) e Liew et al. (2007), respectivamente, por meio das Equações 5 e 6.

$$
\begin{aligned}
& E M P A=\frac{1}{N} \cdot \sum_{i=1}^{n}\left|\frac{O b s_{i}-E s t_{i}}{O b s_{i}}\right| .100 \\
& B I A S=\sum_{i=1}^{n}\left(O b s_{i}-E s t_{i}\right)(100) / \sum_{i=1}^{n}\left(O b s_{i}\right)
\end{aligned}
$$

Onde,

$n=$ número de postos pluviométricos

$O b s_{i}=$ precipitação observada para o posto i, e

$E s t_{i}=$ precipitação estimada por krigagem para a posição do posto $i$.

\section{Resultados e Discussão}

O gráfico box plot e a tendência da precipitação anual acumulada são apresentados na Figura 2 e caracterizam o comportamento geral demonstrado na análise exploratória de dados entre diferentes eventos no presente estudo.

Figura 2 - Gráficos box plot e de tendência obtidos para a precipitação anual acumulada.

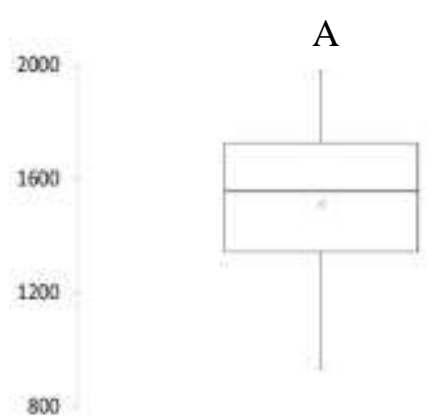

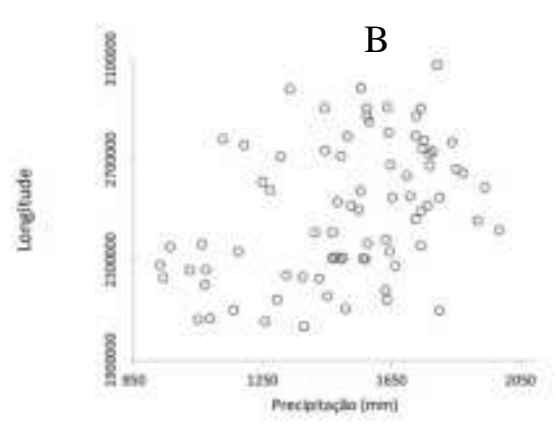

Fonte: Autores (2021).

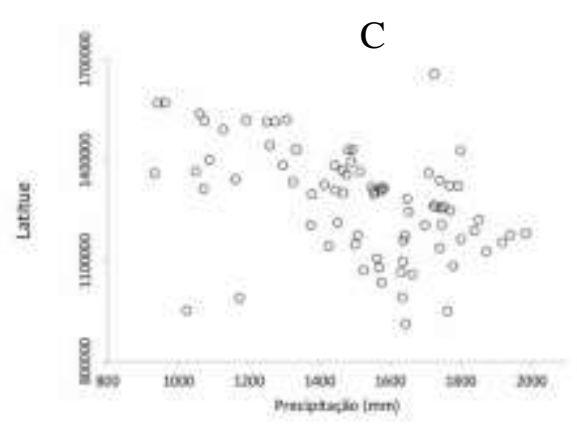

É possível observar na Figura 1B e C, a distribuição de dados satisfatória no sentido Latitude/Longitude indicando boa dispersão dos dados, ou seja, inexistência de tendência espacial dos mesmos, o que segundo Mello \& Viola (2013), permite a verificação da aplicabilidade das técnicas geoestatísticas. Já o gráfico box plot (Figura 1A) permitiu a observação de valores discrepantes no banco de dados que, aliado à realização do teste de Mann-Kendall, permitiu a remoção das estações que apresentaram tendenciosidade da análise geoestatística, visto que estas podem prejudicar a variância aleatória, influenciando diretamente a correlação espacial (Mello et al., 2008).

A Tabela 2 apresenta o resultado do teste de tendência de Mann-Kendall para as 93 estações pluviométricas consideradas inicialmente para a realização deste estudo. 
Tabela 2 - Análise de tendência pelo Teste de Mann-Kendall ao nível de significância $\alpha=0,05$.

\begin{tabular}{|c|c|c|c|}
\hline Município-UF & Mann-Kendall & Município-UF & Mann-Kendall \\
\hline Abreulândia-TO & 0,050 & Gurupi-TO & 0,707 \\
\hline Almas-TO & 0,591 & Alto Parnaíba-MA & 0,570 \\
\hline Alto Paraíso-GO & 0,086 & Itacajá-TO & 0,135 \\
\hline Alto Parnaíba-MA & 0,390 & Itaporã do Tocantins -TO & 0,446 \\
\hline Alvorada-TO & 0,984 & Novo Acordo-TO & 0,186 \\
\hline Ananás-TO & 0,907 & Lizarda-TO & 0,161 \\
\hline Araguacema-TO & 0,000 & Luciara-MT & 0,972 \\
\hline Araguaçu-TO & 1,000 & Rio Sono-TO & 1,000 \\
\hline Araguatins-TO & 0,540 & Miracema do Tocantins -TO & 1,000 \\
\hline Arapoema-TO & 0,123 & Riachão-MA & $\mathbf{0 , 0 3 4 *}$ \\
\hline Aurora do Tocantins-TO & $\mathbf{0 , 0 1 4} *$ & Muricilândia-TO & $0,001 *$ \\
\hline Balsas-MA & 0,536 & Natividade-TO & $0,045 *$ \\
\hline Santana do Araguaia-PA & $0,006 *$ & Nova Roma-GO & 0,669 \\
\hline Sandolândia-TO & 0,398 & Barreiras-BA & 0,171 \\
\hline Alto Boa Vista-MT & 0,748 & Novo Acordo-TO & 0,559 \\
\hline Alto Parnaíba-MA & $0,002 *$ & Novo Planalto-GO & 0,388 \\
\hline Araguaína-TO & 0,187 & Palmeirante-TO & 0,599 \\
\hline Balsas-MA & 0,830 & Palmeirópolis-TO & 0,091 \\
\hline Buritirana-MA & 0,372 & Paraíso do Tocantins-TO & $0,001 *$ \\
\hline Campos Belos-GO & 0,726 & Pindorama do Tocantins-TO & 0,866 \\
\hline Campos Lindos-TO & 0,302 & Araguanã-TO & 0,726 \\
\hline Pium-TO & 0,536 & Pium-TO & 0,528 \\
\hline Carolina-MA & 0,734 & Ponte Alta do Tocantins-TO & 0,786 \\
\hline Colinas-TO & 0,163 & Teresina de Goiás-GO & 0,172 \\
\hline Peixe-TO & 0,138 & Barreiras-BA & 0,086 \\
\hline Bernardo Sayão-TO & 0,212 & Porto Alegre do Tocantins-TO & 0,453 \\
\hline Conceição do Tocantins-TO & 0,860 & Monte Carmo-TO & 0,156 \\
\hline Dianópolis-TO & 0,751 & Pedro Afonso-TO & 0,758 \\
\hline Dois Irmãos do Tocantins-TO & 0,544 & Formoso do Araguaia-TO & 0,792 \\
\hline Dueré-TO & 0,770 & Balsas-MA & 0,915 \\
\hline Porangatu-GO & $0,045 *$ & Redenção-PA & 0,086 \\
\hline Fátima-TO & 0,272 & Conceição do Tocantins-TO & $0,040 *$ \\
\hline Formosa do Rio Preto-BA & 0,113 & São Desidério-BA & $\mathbf{0 , 0 0 5 *}$ \\
\hline Marabá-PA & 0,454 & São Domingos do Capim-PA & 0,311 \\
\hline São Domingos-GO & 0,785 & Novo Santo Antônio-MT & 0,144 \\
\hline Barreiras-BA & $0,001 *$ & São Domingos-GO & 1,000 \\
\hline S. Valério da Natividade & $0,041 *$ & São Félix de Balsas-MA & 0,605 \\
\hline Correntina-BA & 0,183 & S. Félix do Araguaia-TO & 0,536 \\
\hline Nova Olinda-TO & 0,767 & São Sebastião do Tocantins-TO & $0,045 *$ \\
\hline Barreiras-BA & 0,837 & Palmas-TO & 0,624 \\
\hline Sapucaia-PA & $0,017 *$ & Tocantinópolis-TO & 0,823 \\
\hline Fátima-TO & 0,128 & Trombas-GO & 0,427 \\
\hline Marabá-PA & 0,628 & Tupiratins-TO & 0,284 \\
\hline Formosa do Rio Preto-BA & 0,133 & Vila Rica-MT & 0,887 \\
\hline Formoso do Araguaia-TO & 0,833 & Wanderlândia-TO & 0,528 \\
\hline Goiatins-TO & $0,000 *$ & Xambioá-TO & 0,597 \\
\hline Guaraí-TO & 0,260 & & \\
\hline
\end{tabular}

* Indicam que a série histórica apresentou tendência constatada pelo teste realizado.

Nota: Números antecedidos por $(*)$ e municípios em negrito, indicam que há evidências estatística para rejeitar a inexistência de tendência (H0) na série de dados para o período analisado.

Fonte: Autores (2021).

Por meio da Tabela 2, é possível identificar os municípios cujas estações pluviométricas foram reprovadas pelo teste de Mann-Kendall. Desta forma, as estações localizadas nos municípios de Riachão-MA, Muricilândia-TO, Aurora-TO, NatividadeTO, Santana do Araguaia-PA, Alto Parnaíba-MA, Paraíso-TO, Porangatu-GO, Conceição do TO, São Desidério-BA, BarreirasBA, São Valério da Natividade-TO, Sapucaia-PA, Goiatins-TO e São Sebastião do Tocantins-TO foram retiradas do banco de 
dados inicial, o que acarretou a exclusão de 15 estações pluviométricas, para a realização da análise geoestatística a partir das demais 78 estações.

A Figura 3 apresenta os resultados das 15 estações pluviométricas que apresentaram tendência e, por consequência disso, foram retiradas da relação utilizada para análise geoestatística. É possível observar nítida redução dos valores de precipitação ao longo da série histórica para a maior parte das estações excluídas.

Figura 3 - Estações que apresentaram tendência no teste de Mann-Kendall $(\alpha=0,05)$.

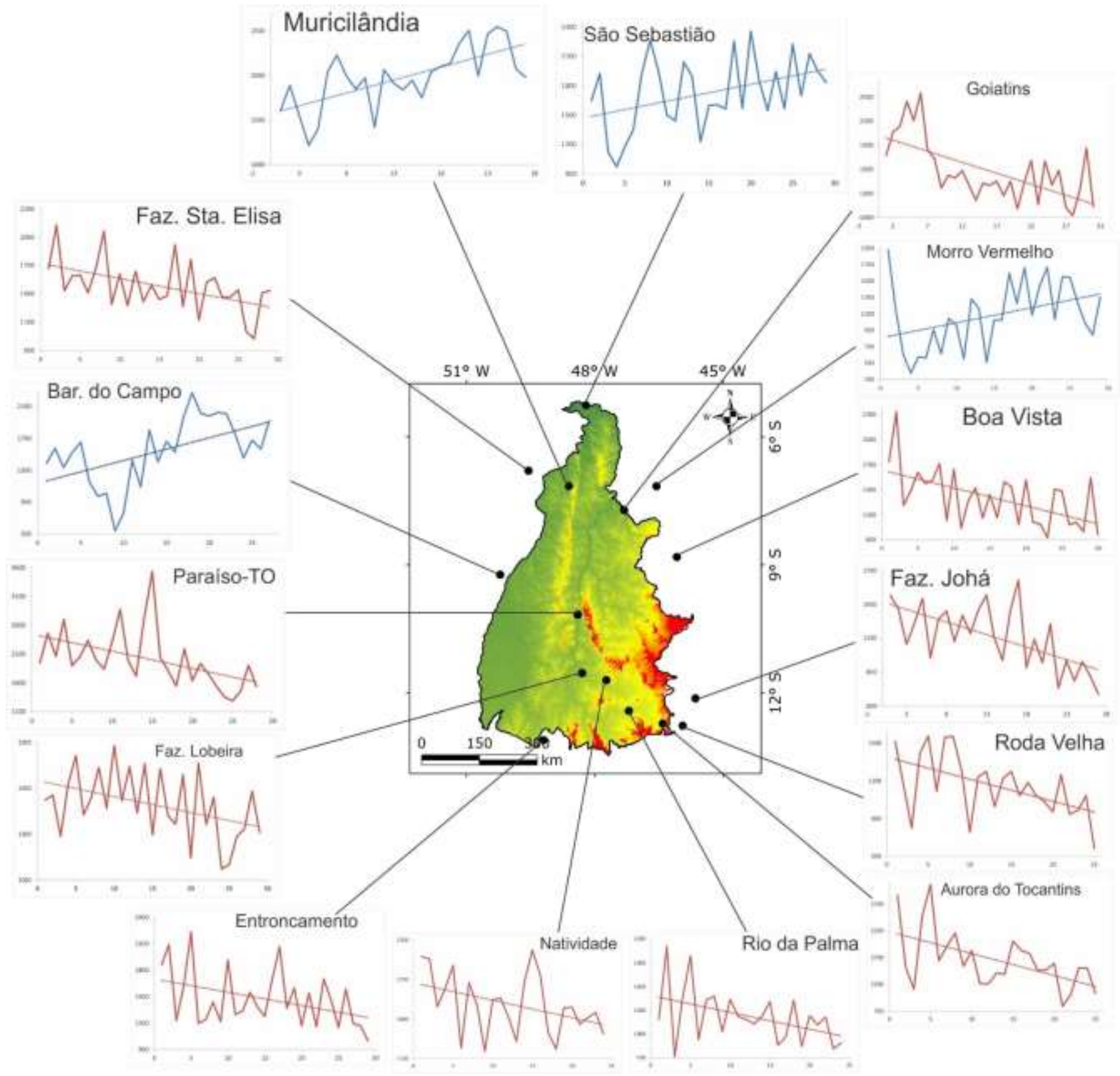

Fonte: ANA. Org.: Autores (2021).

Pode-se constatar que quase todas as estações que apresentaram tendência de redução da precipitação estão localizadas na região central, sul e sudeste do Tocantins. Do total de quinze estações descartadas da análise geoestatística, 11 apresentaram 
redução e quatro tiveram tendência de aumento. Destas, duas estão localizadas fora do estado, Barreira do Campo, situada em Santana do Araguaia-PA e Morro Vermelho, situada em Riachão-MA.

Em estudos sobre elaboração de cartas climáticas para o estado, TOCANTINS (2020) descreve que os dados de 1990 a 2019 apontam a tendência de redução das chuvas em três das quatro estações pluviométricas que se situam na região programa Extremo Norte do Tocantins (Bico do Papagaio), a única que apresenta aumento nos volumes anuais é a estação de São Sebastião do Tocantins. A estação de Muricilândia, que está localizada na região Norte do estado, também demonstrou tendência de redução dos valores de precipitação, como está representado na Figura 3. As estações de Barreira do Campo e Morro vermelho estão localizadas em Santana do Araguaia-PA e Riachão-MA, respectivamente.

As Tabelas 3 e 4 apresentam os parâmetros dos modelos de semivariograma cruzado para os períodos seco, chuvoso e o acumulado anual e mensal, respectivamente, a partir das séries históricas entre 1988 e 2019. É importante destacar que entendese aqui como período seco os meses entre abril e novembro, de acordo com o que foi descrito por Viola et al. (2014) sobre a precipitação no estado do Tocantins, segundo os quais "em termos médios para o Estado, os meses mais chuvosos corresponderam àqueles entre dezembro e março, com lâmina média acumulada que ultrapassou 1.000 mm” (Viola et al., 2014, p. 129).

Tabela 3 - Parâmetros do semivariograma ajustado aos modelos esférico, exponencial e gaussinao: Efeito Pepita (C0), Alcance km (A), Contribuição (C1), Viés Estatístico (Bias \%), Erro Médio Percentual Absoluto (EMPA) e Grau de Dependência Espacial (GDE) para os modelos de semivariograma exponencial e esférico para os períodos seco, chuvoso e anual.

\begin{tabular}{|c|c|c|c|}
\hline Parâmetros & Período seco & Período Chuvoso & Precipitação anual \\
\hline \multicolumn{4}{|c|}{ Modelo Esférico } \\
\hline $\mathrm{C} 0$ & 1227,6 & 7984,9 & 15418,5 \\
\hline $\mathrm{A}(\mathrm{Km})$ & 809 & 541 & 666 \\
\hline $\mathrm{C} 1$ & 21676,8 & 20818,6 & 74000,2 \\
\hline $\operatorname{Bias}(\%)$ & 1,1 & 1,7 & 1,3 \\
\hline EMPA $(\%)$ & 10,3 & 10,24 & 9,7 \\
\hline $\operatorname{GDE}(\%)$ & 94,6 & 72,3 & 82,8 \\
\hline \multicolumn{4}{|c|}{ Modelo Exponencial } \\
\hline $\mathrm{C} 0$ & 0,0 & 5905,5 & 7784,5 \\
\hline $\mathrm{A}(\mathrm{Km})$ & 840 & 634 & 733 \\
\hline $\mathrm{C} 1$ & 20868,5 & 23478,5 & 80421,9 \\
\hline Bias (\%) & 1,0 & 1,7 & 1,3 \\
\hline EMPA $(\%)$ & 10,4 & $10,2 *$ & $9,6^{*}$ \\
\hline $\operatorname{GDE}(\%)$ & 100,0 & 79,9 & 91,2 \\
\hline \multicolumn{4}{|c|}{ Modelo Gaussiano } \\
\hline $\mathrm{C} 0$ & 3012,7 & 10711,4 & 22246,9 \\
\hline $\mathrm{A}(\mathrm{Km})$ & 627 & 473 & 540 \\
\hline $\mathrm{C} 1$ & 19803,5 & 18730,8 & 68098,4 \\
\hline $\operatorname{Bias}(\%)$ & 1,0 & 1,7 & 1,3 \\
\hline EMPA $(\%)$ & $10,2^{*}$ & 10,4 & 9,8 \\
\hline GDE (\%) & 86,8 & 63,6 & 75,4 \\
\hline
\end{tabular}

* Em destaque o modelo com melhor desempenho. Fonte: Autores (2021).

Por meio da observação da Tabela 3 e com base no EMPA, o modelo que obteve o melhor desempenho para o período seco foi o gaussiano $(\mathrm{EMPA}=10,2)$, já para o período chuvoso e o acumulado anual, o modelo exponencial apresentou os 
menores valores do EMPA, 10,2 e 9,6, respectivamente. O valor do EMPA igual a 10,2\% está de acordo com os valores encontrados por Silva Neto et al. (2020b) no mapeamento de chuvas para o Tocantins, onde Bias e EMPA variaram entre 0,9\% e $1,6 \%$ e entre $7 \%$ e $10 \%$, respectivamente.

Nos estudos de Silva et al. (2010) sobre o mapeamento da Erosividade da chuva no vale do Rio Doce, centro-leste de Minas Gerais, o modelo gaussiano obteve também o melhor desempenho, exceto para os meses de junho, novembro e dezembro. Outra situação em que o modelo gaussiano obteve melhor desempenho que os modelos esférico e exponencial é descrita nos trabalhos de Silva Neto et al (2020b) sobre o mapeamento de chuvas intensas para o estado do Tocantins, considerando as situações de chuvas intensas com duração entre 10 e 1440 minutos. Porém, considerando a precipitação máxima diária anual no Tocantins, os referidos autores obtiveram melhor desempenho com o modelo esférico.

A Figura 4 apresenta o semivariograma cruzado para os períodos seco e chuvoso, enquanto a Figura 4 demonstra o ajuste do semivariograma referente à precipitação anual.

Figura 4 - Modelos de semivariograma cruzado ajustados ao semivariograma experimental.

A

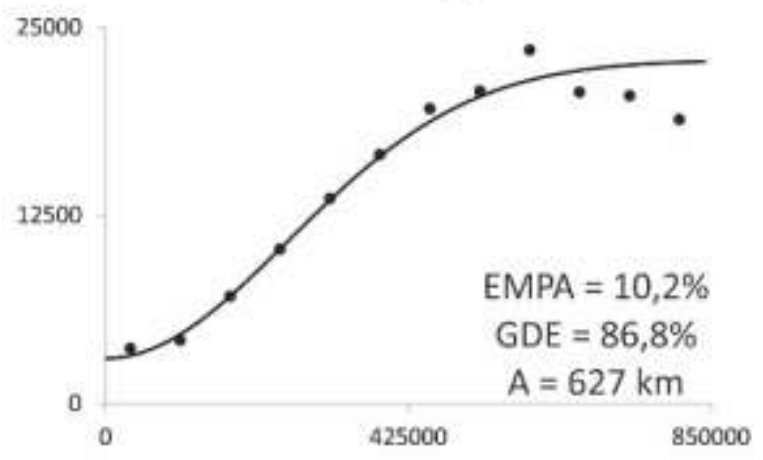

B

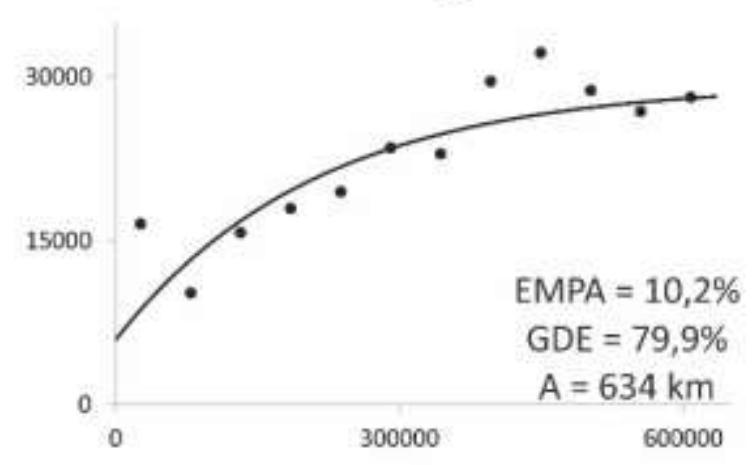

Fonte: Autores (2021).

Por meio da observação da Figura 4, é possível observar boa aderência dos modelos teóricos de semivariograma ajustados para os períodos seco e chuvoso, sendo o melhor desempenho com base no EMPA os modelos gaussiano e exponencial, respectivamente. A distribuição espacial da precipitação anual acumulada pode ser observada a partir da Figura 5. 
Figura 5 - Distribuição espacial da precipitação em mm para o estado do Tocantins para os períodos chuvoso e seco, respectivamente.

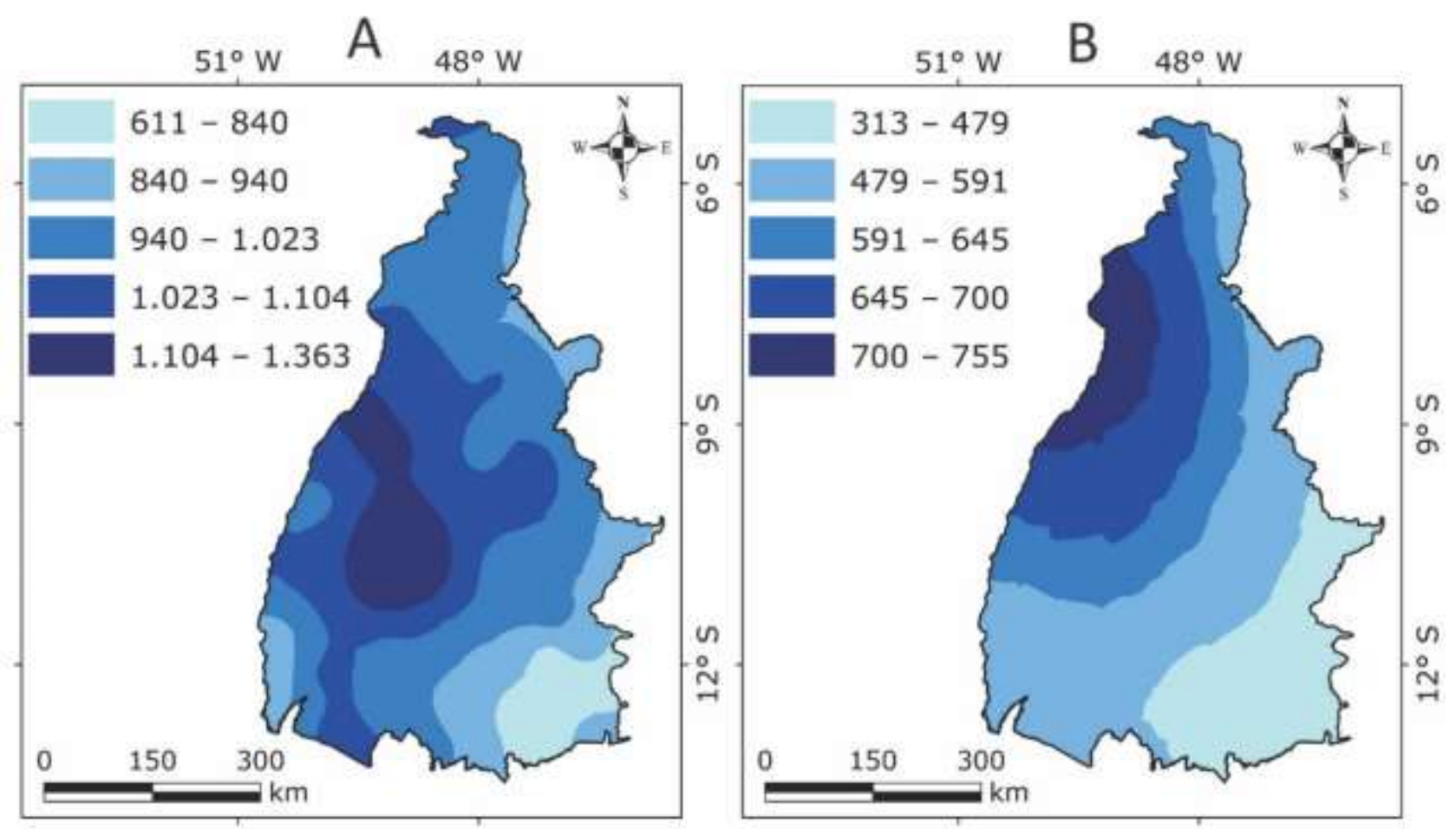

Fonte: Autores (2021).

Com base na Figura 5A, pode-se perceber que durante o período chuvoso, a precipitação no Tocantins concentra-se na porção centro-oeste do estado, variando entre 1104 a 1363 mm, com os menores valores de precipitação anual concentrados a sudeste do estado, com valores entre 611 e 840 mm. Marcuzzo \& Goularte (2013), afirmam que a precipitação anual no estado está concentrada no período chuvoso em 90\%, já no presente estudo, o período chuvoso concentra 63,3\% da precipitação anual. Esta diferença pode ser explicada pelo fato de os autores considerarem como período chuvoso o intervalo de sete meses entre outubro e abril, enquanto neste estudo denomina-se período chuvoso apenas os quatro meses mais chuvosos entre dezembro e março, conforme descrito por Viola et al. (2014). Na Figura 5B pode-se observar que a porção sudeste do Tocantins apresenta os menores valores de precipitação pluvial, variando entre 313 e $469 \mathrm{~mm}$, aumentando gradativamente ao noroeste, onde os valores de precipitação para o período seco variam entre 700 e $755 \mathrm{~mm}$.

Os resultados descritos na Figura 5 corroboram os estudos descritos por TOCANTINS (2012), TOCANTINS (2020) e Pinto et al. (2017), mostrando um incremento no sentido SE - NW. Isso mostra a posição do Cerrado em uma transição entre a Caatinga e a Amazônia. Em vários sentidos, o Tocantins demonstra ser uma área de transição climática, inclusive considerandose as massar de ar.

A precipitação anual e o semivariograma teórico ajustado para o acumulado anual estão representados por meio da Figura 6. 
Figura 6 - Distribuição espacial da precipitação anual e semivariograma teórico ajustado aos modelos esféricos, exponencial e gaussiano.
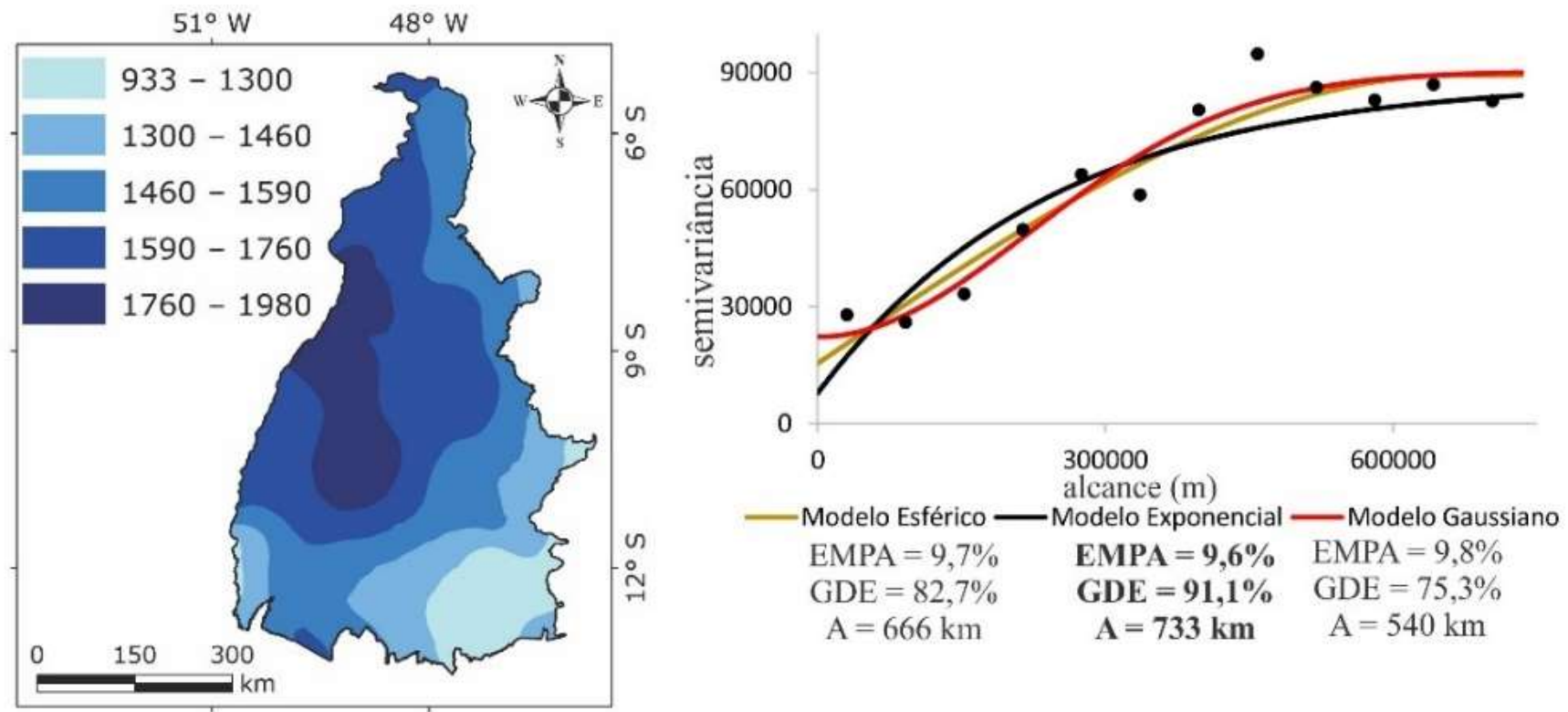

Fonte: Autores (2021).

Pela observação da Figura 6, pode-se inferir que a distribuição da precipitação anual acompanha a distribuição das chuvas durante o período chuvoso, o que significa dizer que a maior parte da precipitação acumulada durante o ano no Tocantins está concentrada durante os meses de dezembro a março, corroborando os estudos de Viola et al. (2014). No entanto, Pinto et al. (2017) descreve que o trimestre mais chuvoso muda ligeiramente no espaço, não sendo o mesmo para todo o estado. "É importante destacar que "Toda a metade oeste do Tocantins sofre a influência de diversos sistemas meteorológicos produtores de chuvas abundantes, citando-se a circulação de oeste da mEc [Massa Equatorial Atlântica], [...], ZCAS [Zona de Convergência do Atlântico Sul], LICON [Linhas de Instabilidade Continental] e VCAN [Vórtice Ciclônico de Altos Níveis], todos com atuação predominantemente entre os meses de outubro a abril" (TOCANTINS, 2020, p. 55).

Com relação ao viés estatístico, conforme Souza et al. (2019), o Bias representa a porcentagem de enviesamento da precipitação especializada pelos interpoladores, onde valores positivos indicam tendência de subestimação e, negativos, de superestimação. Neste estudo, o Bias mensal pode ser observado na Tabela 4, onde é possível inferir que a maioria dos resultados apresentou boa acurácia, indicando que os parâmetros foram ajustados satisfatoriamente. 
Tabela 4. Parâmetros do semivariograma ajustado aos modelos esférico, exponencial e gaussinao: Efeito Pepita (C0), Alcance (A), Contribuição (C1), Viés Estatístico (Bias \%), Erro Médio Percentual Absoluto (EMPA) e Grau de Dependência Espacial (GDE) para os modelos de semivariograma exponencial e esférico para os meses de janeiro a dezembro.

\begin{tabular}{|c|c|c|c|c|c|c|c|c|c|c|c|c|}
\hline Parâmetros & Jan & Fev & Mar & Abr & Mai & Jun & Jul & Ago & Set & Out & Nov & Dez \\
\hline & & \multicolumn{11}{|c|}{ Modelo Esférico } \\
\hline $\mathrm{C} 0$ & 861,1 & 589,9 & 588,7 & 34,4 & 0,0 & 0,0 & 0,0 & 0,0 & 0,0 & 129,1 & 213,0 & 265,4 \\
\hline $\mathrm{A}(\mathrm{Km})$ & 499 & 1281 & 1281 & 1281 & 1281 & 206 & 206 & 122 & 702 & 629 & 108 & 135 \\
\hline $\mathrm{C} 1$ & 1461,4 & 3437,9 & 3871,0 & 5493,2 & 1559,8 & 32,0 & 12,6 & 6,7 & 360,5 & 1123,2 & 371,3 & 1044,7 \\
\hline $\operatorname{Bias}(\%)$ & 2,3 & 2,2 & 2,1 & 2,9 & 3,1 & 24,2 & 73,0 & 26,4 & 5,2 & 3,3 & 2,1 & 2,7 \\
\hline EMPA $(\%)$ & 12,2 & 12,1 & 11,8 & $15,0 *$ & 19,2 & $52,0 *$ & 112,3 & $45,6^{*}$ & 22,5 & 14,6 & 10,5 & 11,8 \\
\hline \multirow[t]{2}{*}{$\operatorname{GDE}(\%)$} & 62,9 & 85,4 & 86,8 & 99,4 & 100,0 & 100,0 & 100,0 & 100,0 & 100,0 & 89,7 & 63,6 & 79,7 \\
\hline & & \multicolumn{11}{|c|}{ Modelo Exponencial } \\
\hline $\mathrm{C} 0$ & 666,6 & 446,2 & 517,6 & 0,0 & 0,0 & 0,0 & 0,0 & 0,0 & 0,0 & 0,0 & 154,9 & 0,0 \\
\hline $\mathrm{A}(\mathrm{Km})$ & 605 & 1281 & 1281 & 1281 & 1281 & 352 & 341 & 122 & 733 & 730 & 145 & 156 \\
\hline $\mathrm{C} 1$ & 1748,0 & 2878,2 & 3058,6 & 4265,0 & 1213,7 & 36,7 & 14,4 & 6,4 & 321,5 & 1278,2 & 467,5 & 1392,7 \\
\hline $\operatorname{Bias}(\%)$ & 2,4 & 2,1 & 2,1 & 3,1 & 3,3 & 27,0 & 83,7 & 28,7 & 5,5 & 3,1 & 2,2 & 2,9 \\
\hline EMPA $(\%)$ & $12,0^{*}$ & $11,9 *$ & $11,7^{*}$ & 15,0 & $19,0 *$ & 52,1 & 119,2 & 47,4 & $22,0 *$ & 14,7 & $10,3^{*}$ & $11,8^{*}$ \\
\hline \multirow[t]{2}{*}{ GDE $(\%)$} & 72,4 & 86,6 & 85,5 & 100,0 & 100,0 & 100,0 & 100,0 & 100,0 & 100,0 & 100,0 & 75,1 & 100,0 \\
\hline & & \multicolumn{11}{|c|}{ Modelo Gaussiano } \\
\hline $\mathrm{C} 0$ & 1075,2 & 988,9 & 965,9 & 405,7 & 65,6 & 2,4 & 1,8 & 0,0 & 34,3 & 254,4 & 297,0 & 471,3 \\
\hline $\mathrm{A}(\mathrm{Km})$ & 440 & 1161 & 1088 & 1281 & 1281 & 175 & 176 & 82 & 545 & 543 & 102 & 120 \\
\hline $\mathrm{C} 1$ & 1281,5 & 3639,5 & 4014,0 & 8162,5 & 2513,6 & 30,3 & 10,9 & 6,3 & 319,7 & 1043,7 & 294,2 & 847,5 \\
\hline $\operatorname{Bias}(\%)$ & 2,4 & 2,3 & 2,4 & 3,4 & 5,2 & 23,6 & 71,1 & 27,6 & 5,4 & 3,3 & 2,1 & 2,7 \\
\hline EMPA (\%) & 12,3 & 13,1 & 12,1 & 15,2 & 20,3 & 58,5 & $110,7 *$ & 47,1 & 22,7 & $14,3^{*}$ & 10,6 & 11,9 \\
\hline GDE (\%) & 54,4 & 78,6 & 80,6 & 95,3 & 97,5 & 92,6 & 86,0 & 99,9 & 90,3 & 80,4 & 49,8 & 64,3 \\
\hline
\end{tabular}

* Em destaque o modelo com melhor desempenho. Fonte: Autores (2021).

A Tabela 4 permite constatar o melhor desempenho do modelo esférico nos meses de abril, junho e agosto (EMPA equivalente a 14\%, 52\% e 45\%, respectivamente), a partir da observação dos menores erros nestes meses, o que corresponde a $20 \%$ das situações analisadas. O modelo exponencial apresentou melhor desempenho durante os meses de janeiro, fevereiro, março, junho, setembro, novembro e dezembro (EMPA variando entre10\% e 22\%, considerando os melhores desempenhos). Nas demais situações analisadas, o modelo gaussiano apresentou EMPA variando entre $14 \%$ e $110 \%$. Deve-se enfatizar que os maiores erros observados foram obtidos para os meses com menor precipitação pluvial, junho, julho e agosto para todos os modelos testados.

Na literatura os valores dos erros estão nos mesmos patamares. Alves et al. (2014) apresentaram valores do EMPA que variaram entre $11 \%$ a $187 \%$, ao estudarem as precipitações prováveis para a bacia do Rio Formoso, também no Tocantins. Notase que os maiores valores também foram registrados para os meses de estiagem. Santos et al. (2011) obtiveram valores do EMPA entre $6,7 \%$ e $25,7 \%$ para a variabilidade da precipitação pluvial na bacia hidrográfica do rio João Leite-GO. Souza et al. (2019), na regionalização climática para o Tocantins, obtiveram valores do EMPA entre 4\% e 58\%.

Mello et al. (2007), ao analisarem a continuidade espacial da Erosividade das chuvas no estado de Minas Gerais, também observaram melhor desempenho do modelo exponencial. Mello \& Viola (2013), em estudos sobre chuvas intensas, fazem também a recomendação pelo uso do modelo exponencial para propostas de mapeamento da variável hidrológica, devido ao bom desempenho observado. Barros et al. (2020) também obtiveram melhor desempenho do modelo exponencial utilizando a geoestatística como ferramenta para investigação da variabilidade da precipitação pluvial para o estado de Pernambuco. 
Na Tabela 4 também podem ser observadas a variação no efeito pepita, que indica haver uma descontinuidade entre valores separados por distância menores que aquele utilizado no intervalo de amostragem. Prólo et al. (2021) afirmam que isso indica a aleatoriedade de um ponto para outro, sendo que, quanto menor seus valores, mais parecidos são os valores vizinhos.

Outro parâmetro essencial para a análise geoestatística é a amplitude do semivariograma (alcance). Trata-se da distância a partir da qual as amostras passam a não apresentar correlação espacial, isto é, a partir da qual a variação média entre duas observações não é mais função da distância entre elas. Este parâmetro indica a homogeneidade das amostras. $\mathrm{O}$ alcance reflete a homogeneidade entre as amostras, quanto maior for o seu valor, mais homogêneo será o fenômeno ou processo estudado (Prólo et al., 2021). No presente estudo, o alcance variou entre $1281 \mathrm{~km}$ para os meses de março, abril e maio, com o modelo exponencial, e $82 \mathrm{~km}$ com o modelo gaussiano para o mês de agosto. O mês de novembro foi o que demonstrou o menor valor da amplitude semivariográfica para todos os modelos testados, variando entre 82 e $122 \mathrm{~km}$. Silva Neto et al. (2020b) encontraram valores do alcance para o modelo de melhor desempenho variando entre 349 e $456 \mathrm{~km}$. Barros et al. (2020) obtiveram valores entre 57 e $85 \mathrm{~km}$. Silva et al. (2010) registraram o alcance variando entre $10 \mathrm{~km}$, em outubro, e $177 \mathrm{~km}$, em junho. Mello \& Viola (2013) descreveram alcance variando de 100 a $450 \mathrm{~km}$ para as durações de 30, 360 e 720 min e de 300 a $550 \mathrm{~km}$ para a duração de 1.440 minutos. O grau de dependência espacial (GDE) determinado neste estudo para a interpolação da precipitação anual no Tocantins variou entre 75,3\% (modelo gaussiano) e 91,1\% (modelo exponencial - melhor desempenho para esta situação). Para a precipitação mensal, os valores obtidos para o grau de dependência espacial para os modelos com melhor desempenho variaram entre $72,4 \%$ e $100 \%$.

Pode-se afirmar que, com a exceção do modelo exponencial para o mês de janeiro $(72,4 \%)$, todos os demais valores são classificados como forte grau de dependência espacial, de acordo com Cambardella (1994). O GDE foi de 86,6\% com modelo com melhor desempenho para o mês de fevereiro, $85,5 \%$ para o mês de março, 86\% para o mês de julho, 80,4\% para o mês de outubro, 75,1\% para o mês de novembro e para todos os outros meses o GDE apresentou 100\% de dependência espacial. Para o período seco, o GDE do modelo com melhor desempenho foi de 86,8\%, enquanto para o período chuvoso foi de 79,9\%.

A Figura 7 apresenta os semivariogramas teóricos ajustados aos modelos que apresentaram melhor desempenho na interpolação, com ênfase no EMPA, Bias e GDE.

Outros estudos enfatizam a importância do GDE na análise geoestatística na espacialização de dados de precipitação. Xavier Júnior et al. (2020) apresentaram este parâmetro sempre inferiores a 70\% para precipitação no estado da Paraíba (fraco e moderado GDE), enquanto Silva et al. (2020), em estudos sobre distribuição espacial de índices climáticos para o estado da Bahia, obtiveram sempre forte grau de dependência espacial, variando entre $85 \%$ e 97\%. Barni et al. (2020), em estudos realizados no estado de Roraima, extremo norte da Amazônia, também descreveram forte dependência espacial (DE) da variável aleatória modelada. 
Figura 7 - Semivariogramas teóricos ajustados para o mapeamento da precipitação mensal no Tocantins.

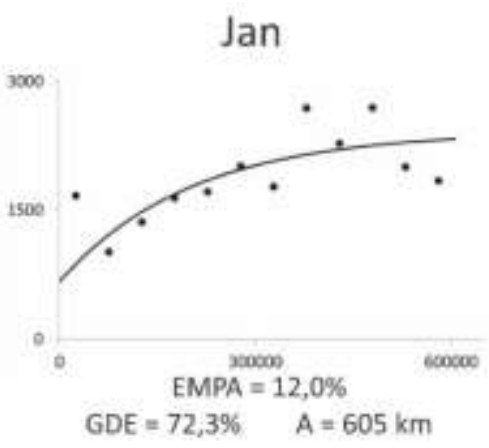

$\mathrm{Abr}$

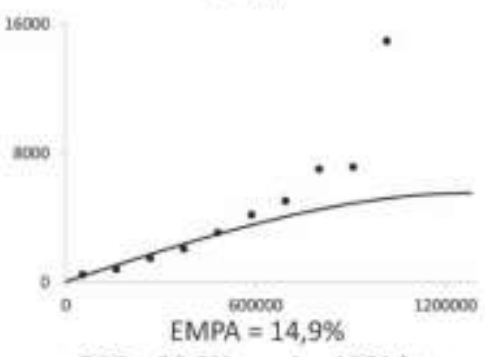

$\mathrm{GDE}=99,3 \% \quad \mathrm{~A}=1281 \mathrm{~km}$

Jul

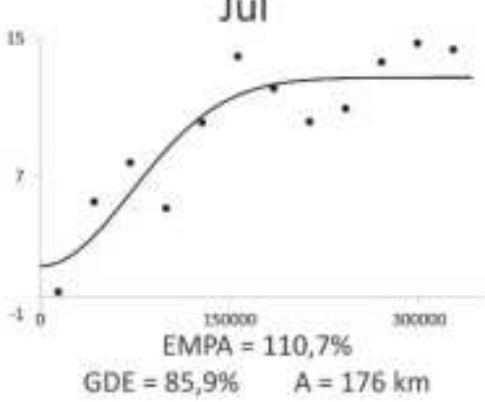

Out

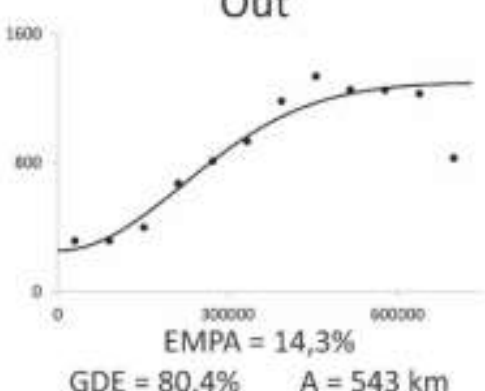

Fev

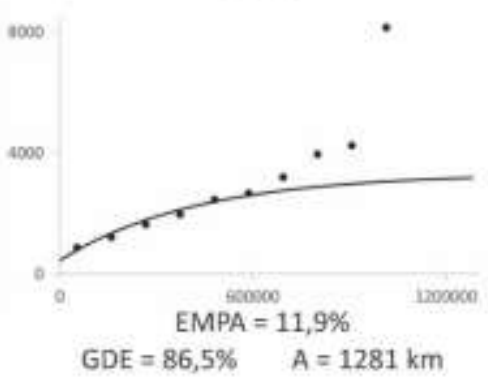

Mai

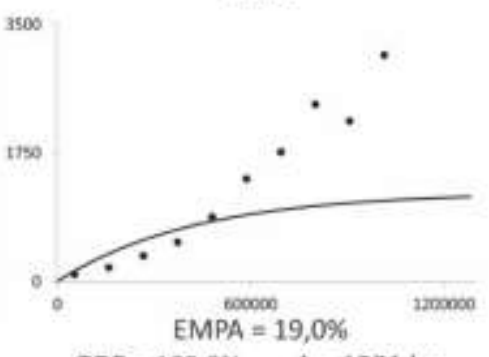

$\mathrm{GDE}=100,0 \% \quad \mathrm{~A}=1281 \mathrm{~km}$

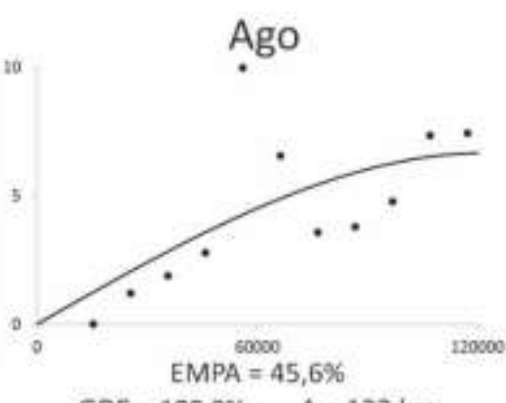

$\mathrm{GDE}=100,0 \% \quad \mathrm{~A}=122 \mathrm{~km}$

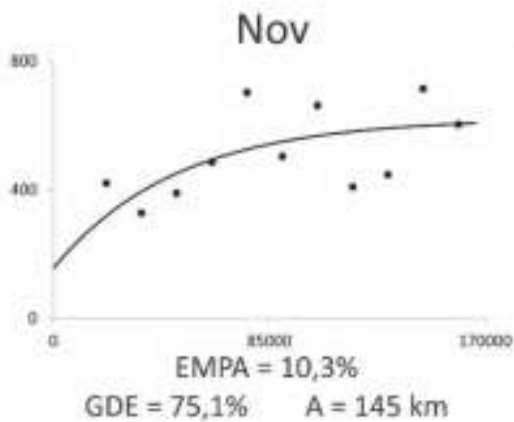

Fonte: Autores (2021).
Mar

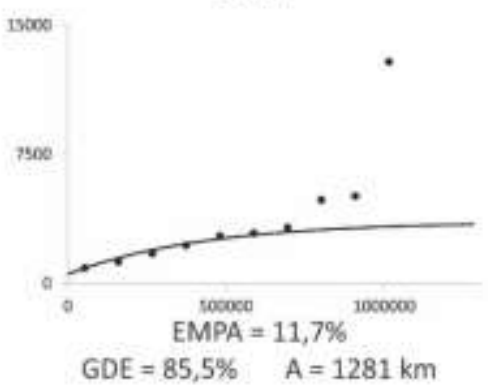

Jun

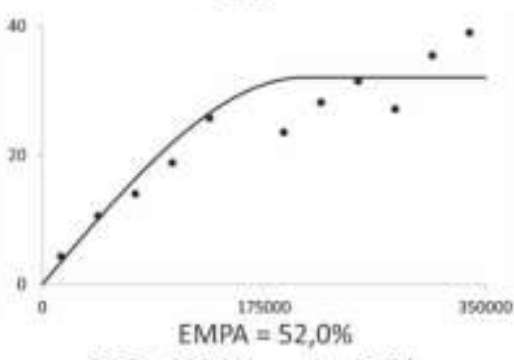

$\mathrm{GDE}=100,0 \% \quad \mathrm{~A}=206 \mathrm{~km}$

Set

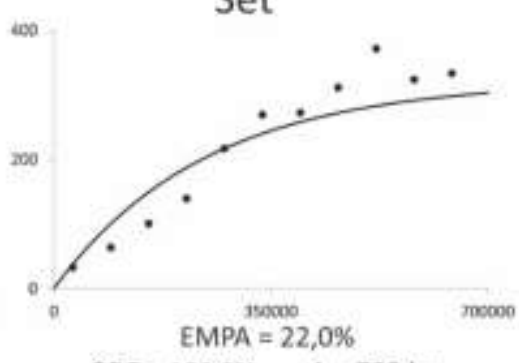

$\mathrm{GDE}=100,0 \% \quad \mathrm{~A}=733 \mathrm{~km}$

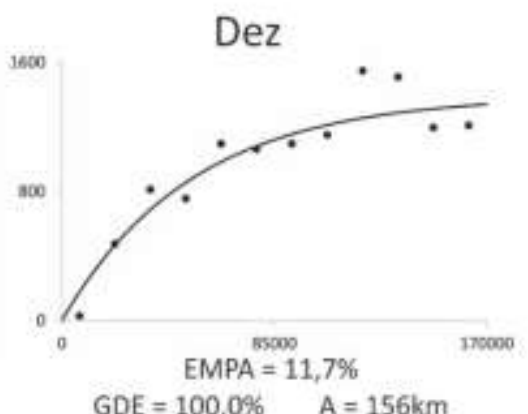

Com base na Figura 7, pode-se observar a adequabilidade das técnicas geoestatísticas na interpolação da precipitação mensal para o estado do Tocantins, a partir da análise do EMPA, Bias e GDE. Estes são parâmetros essenciais para recomendação ou não dos modelos de krigagem testados na interpolação desta variável, em que na maior parte das situações, constata-se boa aderência ao semivariograma teórico dos modelos que apresentaram melhor desempenho e que foram considerados para a realização do mapeamento da precipitação mensal para o Tocantins. A Figura 8 representa o mapeamento da precipitação mensal para o estado do Tocantins. 
Figura 8 - Distribuição espacial da precipitação mensal em mm no estado do Tocantins.
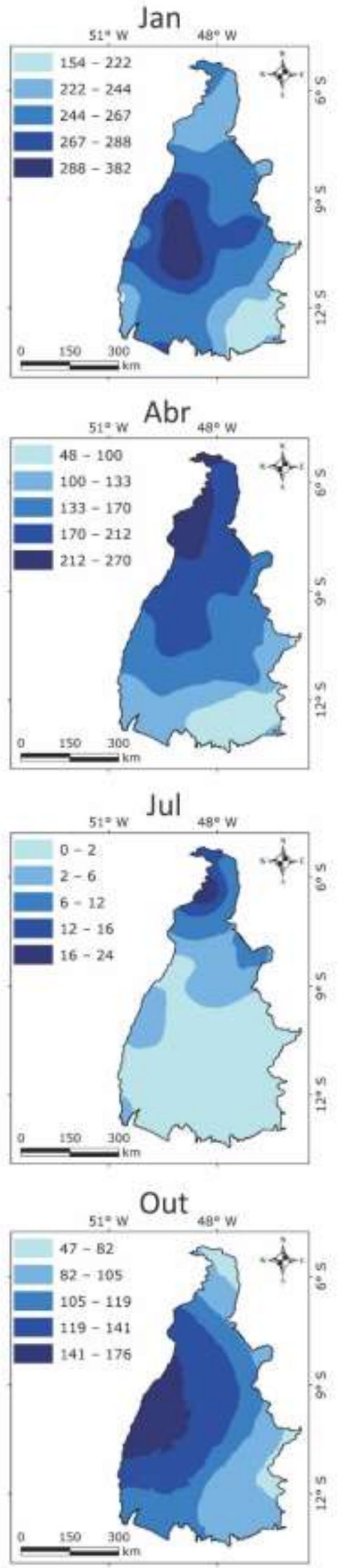
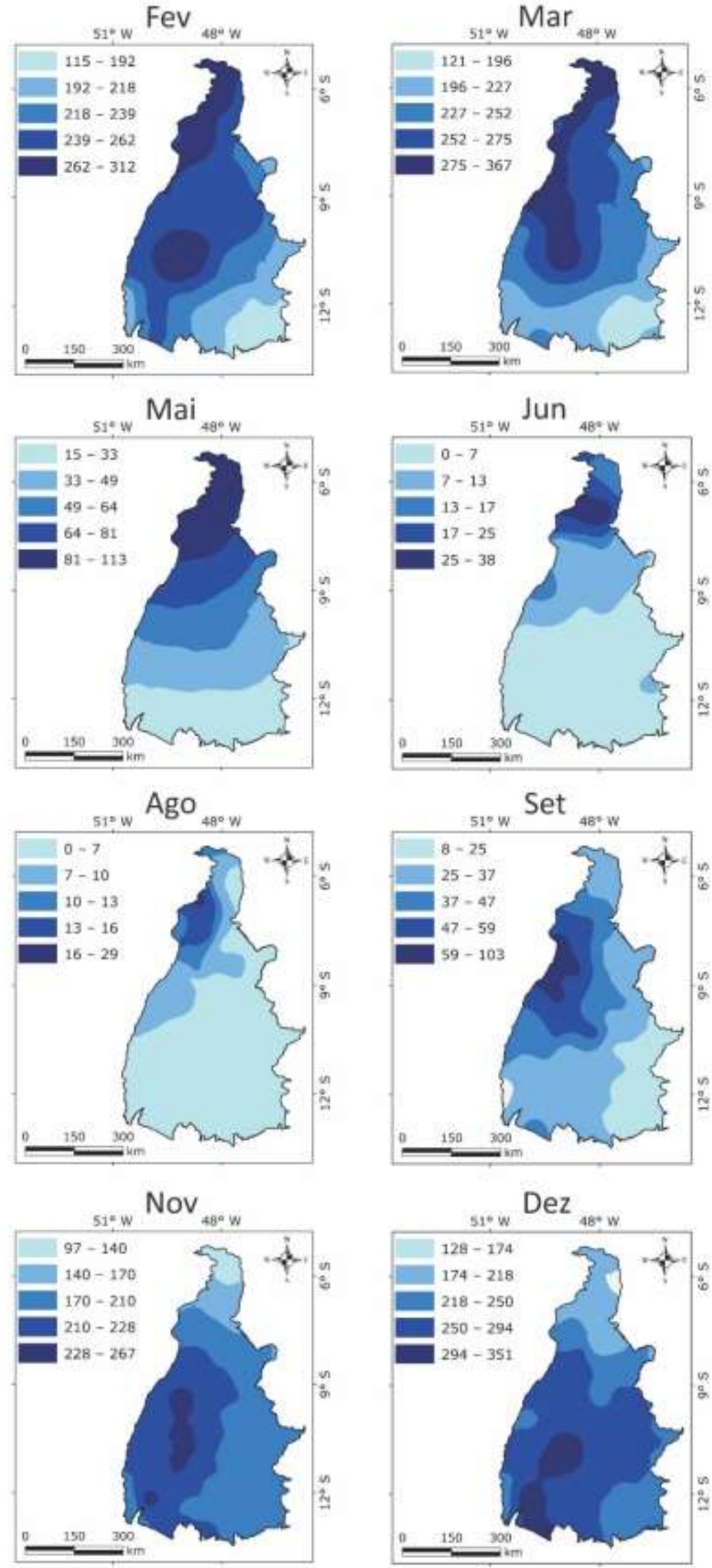

Fonte: Autores (2021). 
A Figura 8 permite observar que na maior parte das situações analisadas a região sudeste do Tocantins apresentou os menores valores de precipitação, enquanto no mês de dezembro podem ser observados até $250 \mathrm{~mm}$ de chuva nesta região, sendo este o mês em que as precipitações são mais expressivas. Durante o mês de julho, considerado o auge do período seco, a porção centro-sul tocantinense apresentou índices muito reduzidos, entre 0 e $2 \mathrm{~mm}$.

Em contrapartida, considerando os meses mais chuvosos, de dezembro a março, a precipitação mensal variou entre 382 mm (janeiro) e $262 \mathrm{~mm}$ (fevereiro). A precipitação, nestes meses, concentra-se na porção centro-oeste do Tocantins, abrangendo o sudoeste tocantinense próximo à Ilha do Bananal durante o mês de dezembro e uma faixa na porção noroeste durante os meses de fevereiro e março. O mês de março também foi responsável pelas maiores lâminas de precipitação mensal acumulada na região do Bico do Papagaio, extremo norte do Tocantins, abrangendo também a porção noroeste onde se localiza o Parque Estadual do Cantão, com extensão até a porção centro-oeste do estado. Os meses entre junho e agosto são o período crítico de estiagem no Tocantins, quando a precipitação no período apresentou variação de 0 a $7 \mathrm{~mm}$.

Os resultados corroboram com os estudos de TOCANTINS (2020), em que está descrito que

no mês de janeiro observa-se uma maior uniformidade na distribuição espacial da chuva, pois este é um mês em que o maior número de sistemas meteorológicos atua sobre Tocantins. Apesar das diversas origens, tais sistemas provocam acumulados de chuva quase igualitários em todo o território. A uniformidade, agora de baixa precipitação mensal, observada no mês de julho, está relacionada com o baixíssimo número de sistemas meteorológicos de macro e mesoescala atuantes no Estado neste mês, destacando-se a atuação da mTa estável (Tocantins, 2020, p. 59).

É importante destacar que no período chuvoso há um ritmo mais oscilante entre os diferentes sistemas atmosféricos geradores de chuva no estado. Esse fato é potencializado pela posição de transição do Tocantins, entre diferenças massas de ar (mTa, mEa mEc e sistemas perturbados vindos de sul, como a frente polar atlântica). No período seco, o ritmo é mais monótono ou repetitivo, com longas atuações da mTa e da mEa em situação de estabilidade (Souza, 2016).

Estes dados também corroboram os estudos sobre a distribuição espacial da precipitação na região do MATOPIBA ${ }^{1}$, realizados por Reis et al. (2020). Os autores afirmam que "os maiores volumes de chuvas apresentam na faixa oeste da região, abrangendo parte do estado do Tocantins, onde os volumes médios ultrapassam valores de 150 mm”. (Reis et al., 2020, p. 1429). Enfatiza-se que os maiores valores de precipitação acumulada na porção ocidental do estado do Tocantins é consequência direta da mEc, cujas características estimula a produção de chuva, como umidade e temperatura do ar mais elevadas. Além disso, a topografia também é um fator que influencia a umidade de origem amazônica, retendo-a a oeste da Serra do Estrondo e à oeste da Serra do Lajeado que, ainda com altitudes pouco acentuadas, dificultam o avanço da corrente de oeste da mEc (TOCANTINS, 2020).

\section{Conclusão}

O modelo exponencial apresentou o melhor desempenho na maior parte das situações analisadas, constatando-se a adequabilidade das técnicas geoestatísticas na interpolação da precipitação mensal para o estado do Tocantins.

A região sudeste do Tocantins apresentou os menores valores de precipitação, enquanto no mês de dezembro os maiores. Durante o mês de julho, considerado o auge do período seco, a porção centro-sul tocantinense apresentou índices muito reduzidos, entre 0 e $2 \mathrm{~mm}$, enquanto nos meses mais chuvosos, de dezembro a março, a precipitação mensal variou entre 382 mm (janeiro) e $262 \mathrm{~mm}$ (fevereiro). Os meses entre julho e setembro são o período crítico de estiagem no Tocantins, quando a

\footnotetext{
${ }^{1}$ MATOPIBA é uma região formada por áreas majoritariamente de cerrado nos estados do Maranhão, Tocantins, Piauí e Bahia, para onde a agricultura se expandiu a partir da segunda metade dos anos 1980. Produz de tubérculos a frutas, passando pela pecuária, mas se destaca mesmo é no cultivo de grãos e fibras, especialmente soja, milho e algodão (EMBRAPA, 2021).
} 
precipitação no período apresentou variação de 0 a $25 \mathrm{~mm}$.

O presente estudo apresenta potencial para ser utilizado como subsídio ao planejamento e gestão de recursos hídricos para o Estado do Tocantins, bem como para o planejamento da produção agrícola. Para estudos futuros, recomenda-se avaliar o desempenho de outros tipos de interpoladores como os de natureza determinística, ampliando assim o conhecimento sobre técnicas de mapeamento da precipitação no estado, relacionando-as profundamente com o tipo de culturas agrícolas praticadas no Tocantins, relacionando-as com os diferentes tipos de agricultura e seus respectivos manejos, praticados com finalidade comercial ou de autossustento no Tocantins.

\section{Agradecimentos}

Ao Instituto Federal de Educação Ciência e Tecnologia do Tocantins, pelo apoio à realização deste estudo por meio do Edital no 17/REI/IFTO, de 12 de março de 2020.

\section{Referências}

Alves, K. C. C. d. L. F., Viola, M. R., Mello, C. R. d., Giongo, M., \& Santos, A. F. d. (2016). Distribuição da precipitação mensal, anual e máxima diária anual na bacia hidrográfica do rio Formoso, Tocantins. Ambiência, 12(1), 49-70.

ANA. Agência Nacional das Águas. (2019). Hidroweb. Sistema de informações hidrológicas. http://hidroweb.ana.gov.br

Andrade, A. R. S., Godoy Neto, A. H., Cruz, A. F. d. S., Andrade, E. K. P., Santos, V. F. d., \& Silva, T. N. P. d. (2018). Geoestatística aplicada à variabilidade espacial e padrões nas séries temporais da precipitação no agreste pernambucano. Journal of Environmental Analysis and Progress, 3(1), 126-145.

ASF DAAC, ALOS. (2020). Conjunto de dados: PALSAR_Radiometric_Terrain_Corrected_low_res; Includes Material @ J JXA/METI 2007. doi.org/10.5067/JBYK3J6HFSVF.

Baptista, G. C. Z., \& Severo, D. L. (2018). Variabilidade espacial e temporal da precipitação de Santa Catarina. Geosul, 33(68), 184-200.

Barni, P. E., Barbosa, R. I., Xaud, H. A. M., Xaud, M. R., \& Fearnside, P. M. (2020). Precipitação no extremo norte da Amazônia: distribuição espacial no estado de Roraima, Brasil. Embrapa Roraima-Artigo em periódico indexado (ALICE).

Barros, T. H. d. S., Bender, F. D., Silva, F. R. B., José, J. V., Costa, J. O., \& Coelho, R. D. (2020). Geoestatística como ferramenta para estudos da variabilidade da precipitação pluviométrica no estado de Pernambuco, Brasil. Agrarian, 13(50), 513-520.

Cambardella, C., Moorman, T., Parkin, T., Karlen, D., Novak, J., Turco, R., \& Konopka, A. (1994). Field-scale variability of soil properties in central Iowa soils. Soil Science Society of America Journal, 58(5), 1501-1511.

Ely, D., \& Dubreuil, V. (2017). Análise das tendências espaço-temporais das precipitações anuais para o estado do Paraná-Brasil. Revista Brasileira de Climatologia, 21(Jul/Dez 2017), 553-569.

EMBRAPA, Empresa Brasileira de Pesquisa Agropecuária. (2021). Matopiba. https://www.embrapa.br/tema-matopiba. Acesso em: 15 março 2021.

ESRI - Environmental Systems Research Institute. ArcGIS 9: Getting started with ArcGIS. (2004). Redlands, 265

Gomes, O. M. (2011). Análise geoestatística da precipitação pluvial no Estado da Paraíba. Revista Brasileira de Geografia Física, 4(1), 92-702.

IBGE. (2004). Instituto Brasileiro de Geografia e estatística. Biomas do Brasil.

Liew, M. W., Veith, T. L., Bosch, D. D., \& Arnold, J. G. (2007). Suitability of SWAT for the conservation effects assessment project: Comparison on USDA agricultural research service watersheds. Journal of Hydrologic Engineering, 12(2), 173-189.

Marcuzzo, F. F. N., \& Goularte, E. R. P. (2013). Caracterização do Ano Hidrológico e Mapeamento Espacial das Chuvas nos Períodos Úmido e Seco do Estado do Tocantins. Revista Brasileira de Geografia Física, 6(01), 91-99.

Mello, C. R., Viola, M. R., Curi, N., \& Silva, A. d. (2012). Distribuição espacial da precipitação e da erosividade da chuva mensal e anual no estado do Espírito Santo. Revista Brasileira de Ciência do Solo, Viçosa, 36(6), 1878-1891.

Mello, C. R., Sá, M. A. C., Curi, N., Mello, J. M., Viola, M. R., \& da Silva, A. M. (2007). Erosividade mensal e anual da chuva no Estado de Minas Gerais. Pesq. agropec. bras., Brasília, 42(4), 537-545.

Mello, C. R., \& Viola, M. R. (2013). Mapeamento de chuvas intensas no estado de Minas Gerais. Revista Brasileira de Ciência do Solo, 37, $37-44$.

Mello, C. R., Viola, M. R., Mello, J. M. d., \& Silva, A. M. d. (2008). Continuidade espacial de chuvas intensas no estado de Minas Gerais. Ciência e Agrotecnologia, 32, 532-539. 
Oliveira, W. P., Silva, M. A. V., Souza, S. A., Santana, C. C., \& Oliveira Junior, A. d. R. (2017). Caracterização da variabilidade espacial e temporal da precipitação pluviométrica do Centro Sul Baiano. Revista Brasileira de Geografia Física, 10(4), 1143-1151.

Penereiro, J. C., Martins, L., \& Beretta, V. (2015). Identificação de tendências sazonais dos regimes climático e hidrológico na bacia hidrográfica dos rios Tocantins e Araguaia, Brasil. Revista Geográfica Acadêmica, 9(1), 52-72.

Penereiro, J. C., Martins, L. L. S., \& Beretta, V. Z. (2016). Variabilidades e tendências interanuais em medidas hidro-climáticas na região hidrográfica do Tocantins-Araguaia, Brasil. Revista Brasileira de Climatologia, 18, 219-241.

Pinto, P. H. P., Souza, L. B. e., Zavattini, J. A., \& Crhistofoletti, A. L. H. (2017). O regime pluviométrico do estado do Tocantins, Brasil, no período de 19862005: variações espaciais. Interface, 1(13), 62-77.

Prólo, T. T., Silva Neto, V. L., Carmo, E. L. d., Silveira Junior, O., \& Silva, L. L. d. (2021). Chuvas intensas na bacia do rio Manuel Alves da Natividade, Tocantins, Brasil. Research, Society and Development, 10(2), 1-24. 10.33448/rsd-v10i2.12673

Reis, L. C., Silva, C. M. S., Bezerra, B. G., \& Spyrides, M. H. C. (2020). Caracterização da variabilidade da precipitação no MATOPIBA, região produtora de soja. Revista Brasileira de Geografia Física, 13(04), 1425-1441.

Santos, E. H. M. d., Griebeler, N. P., \& oliveira, L. F. C. d. (2011). Variabilidade espacial e temporal da precipitação pluvial na bacia hidrográfica do Ribeirão João Leite-GO. Engenharia Agrícola, 31, 78-89.

Santos, S. R. Q. d., Braga, C. C., Campos, T. L. d. O. B., Brito, J. I. B. d., \& Santos, A. P. P. d. (2014). Variabilidade da Precipitação no Estado do Pará por meio de Análise em Componentes Principais. Revista Brasileira de Geografia Física, 7(3), 615-627.

Silva, M. A., Silva, M. L. N., Curi, N., Santos, G. R., Marques, J. J. G. S. e. M., Menezes, M. D., \& Leite, F. P. (2010). Avaliação e espacialização da erosividade da chuva no Vale do Rio Doce, Região Centro-Leste do Estado de Minas Gerais. Revista Brasileira de Ciência do Solo, Viçosa, 34(4), 1029-1039.

Silva, N. D., Oliveira, A. S., \& Souza, J. S. (2020). Análise espacial de índices climáticos no estado Bahia, Brasil. Revista Geama, 6(2), 34-42.

Silva Neto, V. L., Viola, M. R., Mello, C. R., Silva, D. D., \& Giongo, M. (2020a). Precipitação Máxima Provável no Tocantins: Primeira aproximação pelo método estatístico de Hershfield. Revista Brasileira de Climatologia, 27, 660-769.

Silva Neto, V. L., Viola, M. R., Mello, C. R., Silva, D. D., Giongo, M., \& Pereira, S. B. (2020b). Mapeamento de Chuvas Intensas para o Estado do Tocantins. Revista Brasileira de Meteorologia, 35(1), 1-11.

Souza, F. H. M., Viola, M. R., Avanzi, J. C., Giongo, M., \& Filho, M. V. (2019). Thornthwaite's Climate Regionalization for the State of Tocantins, Brazil. FLORESTA, 49(4), 10. doi: 10.5380/rf.v49i4.59188

Souza, L. B. (2016). variabilidade e suscetibilidade climática: implicações ecossistêmicas e sociais. In Anais, Simpósio Brasileiro de Climatologia Geográfica, (pp. 2266-2277). Goiânia-GO.

Tocantins. (2020). Secretaria da Fazenda e Planejamento. Superintendência de Planejamento Governamental. Diretoria de Gestão de Informações Territoriais e Socioeconômicas. Gerência de Zoneamento Territorial. Palmas: SEFAZ/GZT. Projeto de Desenvolvimento Regional Integrado e Sustentável. Elaboração das Cartas Climáticas do Estado do Tocantins, (1). 464 p., Ilust.

Tocantins. (2012). Secretária de Planejamento. Atlas do Tocantins: Subsídios ao Planejamento da Gestão Territorial. Superintendência de Planejamento e Gestão central de Políticas Públicas. Diretoria de Zoneamento Ecológico-Econômico - DZE. Organizado por. Borges, R. S. T.; Dias, R. R.; Sousa, P. A. B. (orgs). Seplan, p.80.

Viola, M. R., Avanzi, J. C., Mello, C. R. d., Lima, S. d. O., \& Alves, M. V. G. (2014). Distribuição e potencial erosivo das chuvas no Estado do Tocantins. Pesquisa Agropecuária Brasileira, 49, 125-135.

Viola, M. R., Mello, C. d., Pinto, D. B., Mello, J. d., \& Ávila, L. F. (2010). Métodos de interpolação espacial para o mapeamento da precipitação pluvial. Revista Brasileira de Engenharia Agrícola e Ambiental, 14(9), 970-978.

Xavier Júnior, S. F. A., Jale, J. d. S., Stosic, T., Santos, C. A. C. d., \& Singh, V. P. (2020). Precipitation trends analysis by Mann-Kendall test: a case study of Paraíba, Brazil. Revista Brasileira de Meteorologia, 35(2), 187-196. 